\title{
A PRODUÇÃO DO ESPAÇO E A APROPRIAÇÃO DE COMUNS URBANOS AMAZÔNICOS: MERCADIFICAÇÃO, CONFLITOS E RESISTÊNCIAS NA ORLA FLUVIAL DA CIDADE MARABÁ-PA
}

The production of space and the appropriation of urban amazon commons: mercadification, conflicts and resistance in the waterfront of the city of Marabá-PA

Michel de Melo Lima *

*Doutorando no PPG em Desenvolvimento Sustentável do Trópico Úmido - UFPA - mmlgeo@hotmail.com.

Recebido em 14/05/2018. Aceito para publicação em 25/06/2018.

Versão online publicada em 10/08/2018 (http://seer.ufrgs.br/paraonde)

\begin{abstract}
Resumo: As orlas fluviais das cidades amazônicas são espaços que, desde o início do processo de ocupação regional até período atual, apresentam intensa relação econômica, funcional e simbólico-cultural com a dinâmica da natureza (floresta e os rios). Diante desse contexto, o presente trabalho analisa a produção do espaço e a apropriação dos comuns urbanos amazônicos em face do processo de modernização (projetos infraestruturais, turísticos e hidrelétricos) da orla de Marabá, uma cidade que exerce grande centralidade na região do sul/sudeste paraense. A análise constatou, por fim, que as dinâmicas modernizantes e empreendedoras que se dão de forma conflituosa sobre esse espaço, subtraem os comuns urbanos (rio e a orla), sufocando o vivido ribeirinho existente.
\end{abstract}

Palavras-chave: Produção do Espaço; Modernização; Comuns Urbanos; Amazônia; Orla Fluvial.

\begin{abstract}
The waterfronts of the Amazonian cities are spaces that, from the beginning of the process of regional occupation until the current period, present an intense economic, functional and symbolic-cultural relationship with the dynamics of nature (forest and rivers). Facing this context, this work analyzes the production of space and the appropriation of the urban Amazon commons under the modernization process (infrastructural, touristic and hydroelectric projects) of the Marabá's waterfront, a city that exerts great centrality in the South / Southeast regions of the Pará state. Finally, the analysis showed that the modernizing and entrepreneurial dynamics of this area, which are in conflict with each other, subtract the urban commons (river and waterfront), suffocating the existent riverside man.
\end{abstract}

Key-words: Production of Space; Modernization; Urban Commons; Amazon; Waterfront.

\section{Introdução}

As orlas fluviais das cidades amazônicas são espaços que, desde o início do processo de ocupação regional, apresentam íntima relação com a dinâmica da natureza. Por conta disso, configuram formas-conteúdo com os quais os amazônidas se identificam, moram, tiram o seu sustento e desenvolvem práticas socioespaciais cotidianas que estão ligados ao tempo lento do rio e da floresta (TRINDADE JR.; SANTOS; RAVENA, 2005), numa multiplicidade de dimensões (econômica, funcional e simbólico-cultural) e em diferentes escalas, que articulam, de forma dialética e no (des)encontro de temporalidades sociais, uma ordem próxima (local e regional) e uma ordem distante (nacional e global).

Assim, as orlas fluviais, importantes comuns urbanos (Harvey, 2014) amazônicos, ao sintetizarem relações sociais e uma morfologia material ligada às águas, se referem à espaços socialmente produzidos pouco modernos do ponto de vista dos fixos existentes, mas de grande difusão de conteúdos sociais pautados na interface floresta-rio que são essenciais ao se pensar modos de vida e o cotidiano de diversas cidades localizadas nas margens dos cursos fluviais. 
Por outro lado, essa dinâmica socioespacial ligada aos rios e à floresta amazônica não se mantém inalterada em face das ações do Estado e das políticas governamentais iniciadas a partir da década de 1960, da inserção de outros modais de transporte (notadamente o rodoviário) e das ações de grandes grupos econômicos e de grandes projetos inseridos no espaço regional.

É nesse sentido, ao pensar a produção do espaço regional e urbano amazônico, que oliveira (1999) destaca que para diversos agentes/grupos sociais localizados nas cidades e no campo, a "natureza" (rios, orlas, ilhas e a floresta) são tratados enquanto necessidade de uso e de trabalho. Por conta disso, deles é retirado principalmente o necessário para sobreviver, para construir um abrigo, ou, ainda, são considerados referenciais de vida, de sentimentos, de emoções, de festa e de encontro; usos, práticas e vivências que não tem na lógica de acumulação do capital o seu principal referencial de reprodução social.

Por outro lado, para outros (Estado, grandes empresas, agências financiadoras multilaterais etc.), estes elementos regionais são vistos somente como potenciais recursos a serem aproveitados através dos mais variados tipos de empreendimentos econômicos (minerais, vegetais, turísticos, energéticos, logísticos). Os referidos e contraditórios interesses podem ocasionar estranhamentos, tensões e até mesmo conflitos entre estes agentes/grupos no âmbito da produção e reprodução do espaço regional (OLIVEIRA, 1999).

Dessa forma, o presente trabalho analisa a produção do espaço e a apropriação dos comuns urbanos amazônicos diante do processo de modernização (projetos infraestruturais, turísticos e hidrelétricos) da orla fluvial de Marabá, uma cidade que exerce importante centralidade econômicopolítica na região do sul/sudeste paraense.

A primeira seção do trabalho aborda os elementos referentes ao marco teórico (comuns urbanos, modernização do espaço amazônico etc.) que instrumentalizou a análise. Na segunda seção realiza-se uma retomada histórica e geográfica do processo de produção do espaço da frente fluvial da cidade de Marabá, no intuito de entender como se desenvolveu, ao longo do tempo, a relação cidade-rio e a apropriação de seus comuns urbanos. A terceira seção é onde são apresentados os comuns urbanos e onde são analisados os resultados do processo de modernização do espaço e das tendências do empreendedorismo urbano existente na orla de Marabá.

Por fim, o presente trabalho, ao destacar o uso comum dos rios e da orla fluvial da cidade de Marabá, busca reconhecer a pluralidade de agentes e de práticas socioespaciais responsáveis pela produção do espaço das orlas amazônicas, assim como pretende subsidiar políticas públicas mais alinhadas às especificidades urbanas regionais.

\section{A produção do espaço e os comuns urbanos amazônicos}

A colonização portuguesa na Amazônia brasileira, um produto de interesses políticos e econômicos de potências europeias (Portugal e Espanha), se deu através da criação de aglomerações e fortins ao longo dos cursos fluviais, em sítios estratégicos na interseção entre os cursos d'água e a floresta, com o objetivo de conquista, exploração de produtos extrativistas, transportes de mercadorias, aprisionamento de índios e defesa do território. Dessa forma, os rios foram essenciais para a circulação de informações, para o domínio político e, posteriormente, para irradiação de novos modos de vida associados a diferentes temporalidades e espacialidades (OLIVEIRA, 2000; CASTRO, 2008), sejam elas consideradas mais tradicionais, sejam elas mais pautadas na modernidade capitalista.

Assim, em ambientes urbanos, atualmente os rios são importantes para obtenção de recursos (água e o pescado), para o desenvolvimento da circulação fluvial em diferentes escalas, para o turismo, para a geração de energia hidroelétrica, para usos e práticas associados ao lazer e ao consumo improdutivo do espaço, e pela identificação, de diversos grupos sociais, com o tempo lento da natureza. 
Além dos rios e todos os seus significados, diversas atividades permeadas por usos materiais e/ou simbólicos associados à floresta são constatadas nas cidades amazônicas, como destaca Castro (2008), notadamente através de processos de trabalho que envolvem a transformação e/ou utilização de produtos extrativistas (madeiras, frutas, ervas, sementes), na caça, no artesanato, nas festas de santo etc.

Assim, floresta e rio se encontram, conformando elos relacionais urbanos que não necessariamente tem na lógica de reprodução capitalista o seu principal referencial de reprodução social. E dentre esses elos, destacam-se os que se materializam nas orlas fluviais das cidades amazônicas, espaços socialmente produzidos ${ }^{1}$ que são permeados por uma morfologia material e social na qual se desenvolvem cultivos de várzeas; onde se obtém o peixe que é utilizado como alimento ou comercializado nos mercados, nas feiras e nos trapiches; de onde muitas vezes é retirada a água para o uso doméstico ou mesmo para o consumo próprio; de onde, por meio da circulação fluvial de menor porte, dos improvisados portos e do amontoado de pequenas embarcações (barcos, canoas, rabetas etc.), interagem ribeirinhos das ilhas e os citadinos; das práticas religiosas e das festas de santo; da construção naval de pequeno porte; do lazer associado ao consumo improdutivo nos banhos de rio das crianças e jovens; e da identificação com o tempo lento da natureza.

Por conta de todos esses usos e dessa representatividade regional, as orlas e os rios podem ser considerados comuns urbanos essenciais ao se pensar o cotidiano de diversas cidades que apresentam cursos fluviais.

Para Harvey (2014), os comuns urbanos são todos os recursos socialmente definidos e provenientes da relação sociedade-natureza, ao longo do tempo, abertos para a coletividade (ideia de uso e apropriação em benefício mútuo) em um determinado referencial espacial. Esses bens vão desde o ambiente socialmente construído, aos avanços e inovações tecnológicos, as práticas socioculturais, as relações econômicas, aos serviços etc., e sua utilização pode ser tanto exclusiva de um grupo social, quanto parcial ou totalmente aberta para diversos outros grupos. Por conta disso, os comuns são permeados tanto pela ideia de exclusividade, quanto de livre acesso, de acesso regulado, policiado ou mesmo administrado. É nesse sentido que é por meio dos referidos elos materiais e imateriais existentes entre os rios, floresta e orlas amazônicas, que se produzem comuns urbanos e solidariedades sociais (HARVEY, 2013; 2014) locais e regionais.

Por outro lado, esses comuns urbanos não podem ser considerados "parados no tempo", pois suas dinâmicas socioespaciais também são, de diversas maneiras e intensidades, solapadas pelo processo de modernização recente da Amazônia e de suas frentes fluviais urbanas.

0 processo que ocorre nas orlas marítimas e fluviais de cidades de importância regional, nacional e internacional, está ligado ao que Harvey (2005) denominou de empreendedorismo urbano, que seria o processo de amoldamento e/ou adequação dos espaços das cidades às necessidades do mercado e do capital no atual contexto de globalização.

Assim, é através dessa situação de aproveitamento capitalista, de consumo no/do espaço (LEFÈBVRE, 1974), que se pode vislumbrar a tendência que está se rebatendo nas orlas da Amazônia de diversas cidades, nas quais diversas propostas de intervenção intra-urbanas que buscam "resgatar a face ribeirinha" são elaboradas. São projetos de renovação urbana que, no geral, buscam maximizar o aproveitamento capitalista desses espaços e que pouco levam em consideração particularidades socioespaciais locais e regionais (TRINDADE JR.; SILVA; AMARAL, 2008).

Dessa forma, a tendência à mercadificação dos espaços de orla e, consequentemente, dos comuns urbanos, se dá a partir do desenvolvimento de ações, de políticas públicas e pela difusão de uma urbanização empreendedora (patrocinada pelo Estado e pelas parcerias público-privadas

\footnotetext{
10 espaço socialmente produzido, categoria central e base analítica da presente proposta, é aquele dos grupos, dos homens enquanto seres sociais que produzem a sua vida, a sua história, a sua consciência, o seu mundo. Ele está vinculado à prática social e, por isso, serve tanto como instrumento de pensamento como de ação, apontando possibilidades e alternativas que se manifestam a partir da imbricação de diferentes modos de produção social. Apresenta um conteúdo sensível, material, vivido e prático. Trata do conjunto da sociedade e não apenas de um grupo ou classe, reconhecendo a existência de conflitos em uma perspectiva dialética. Por conta disso, é condição (CARLOS, 2011), produto e meio de reprodução das relações sociais (LEFÈBVRE, 1974; 2006; 2008a e 2008b).
} 
estabelecidas) assentadas no aproveitamento do potencial das frentes fluviais para o turismo, para o uso das amenidades naturais, para o estabelecimento de atividades recreativas, para o transporte fluvial de maior porte, para a realização de grandes festas e micaretas, para a geração de energia hidroelétrica etc. É nesse sentido que a generalização dessas intervenções urbanas como difundidos modelos de "sucesso", ao levar em consideração principalmente as potencialidades de exploração econômico-capitalista das orlas fluviais, acabam negando, tanto o vivido ribeirinho, quanto os comuns urbanos que possibilitam a sua reprodução.

\section{Os rios, a orla de Marabá e a mercadificação de comuns urbanos}

A origem da cidade de Marabá está ligada ao contexto do espaço regional amazônico durante o século XIX, período em que desponta a atividade econômica ligada ao extrativismo da goma elástica da borracha. 0 crescimento econômico e demográfico proporcionado pela referida atividade extrativista demandou a expansão da produção agrícola e da pecuária para atender às necessidades alimentares da capital do Estado (Belém).

É nesse contexto que, na sub-região do sudeste paraense se dá a fundação, por Carlos Gomes Leitão, no ano de 1895, do Burgo Agrícola do Itacaiúnas, a 8 quilômetros da foz do rio Itacaiúnas (VELHO, 1972). No entanto, as dificuldades pelas quais passaram o burgo (insalubridade do sítio) e a descoberta do caucho, um tipo de goma elástica provinda da castanheira, consistem em fatores que contribuíram decisivamente para o seu despovoamento e para a sua desagregação (EMMI, 1999).

Assim, por conta de vantagens locacionais como a facilidade de circulação e comunicação por meio das vias fluviais, os caucheiros e comerciantes (responsáveis por fornecer, pelo sistema de aviamento, as mercadorias necessárias ao internato na mata) concentraram-se na ponta de terra situada na confluência dos rios Tocantins e Itacaiunas (EMMI, 1999). É nesse espaço que se forma, em 7 de julho de 1898, o aglomerado que daria origem à cidade de Marabá (VELHO, 1972).

Os rios Tocantins e Itacaiúnas, por possibilitarem o início da circulação de mercadorias, informações e pessoas, e o desenvolvimento de atividades, tais como a comercialização do caucho, do ouriço da castanha e a extração de cristal de rocha e diamantes, foram fundamentais para a formação do aglomerado populacional que deu origem à cidade de Marabá, assim como influenciaram a expansão da sua malha urbana, que durante boa parte da primeira metade do século XX, acompanhou os cursos fluviais. Além disso, pela importância que eles ainda hoje apresentam para o desenvolvimento da vida no espaço de orla, estes rios configuram elementos fundamentais para os grupos sociais que desenvolvem práticas ligadas às águas, como a sua utilização para a obtenção de recursos (água e o pescado), como meio de circulação (transporte fluvial) e como referencial simbólico e cultural (LIMA, 2013; 2016).

O período recente, no entanto, se destaca pela construção de pontes sobre os rios, pelo estímulo ao comércio, as atividades de recreação e de turismo por parte do poder público e coalização de forças empreendedoras locais e regionais. É nesse momento que se inicia a substituição da população original e são realizadas intervenções como a construção do calçadão e do cais de arrimo, de praças, de quadras de esportes, de um museu e de um residencial que não leva em consideração as especificidades ribeirinhas locais. Além disso, atualmente estão previstas diversas intervenções/obras para a orla de Marabá, são elas: (a) a construção de um porto que daria suporte as atividades siderúrgicas da ALPA (Aços Laminados do Pará), o que transformaria a orla em espaço de escoamento de diversos produtos, inclusive industrializados; (b) a edificação da Hidrelétrica de Marabá, um empreendimento que tem por objetivo atender as demandas locais e regionais de energia; (c) a implantação da Hidrovia Araguaia-Tocantins, que visa ao surgimento de um novo eixo centro-norte de transporte fluvial, com ênfase na circulação das mais variadas cargas, principalmente commodities. De maneira geral, são intervenções de pequeno, médio e grande porte que imprimirão profundas mudanças na orla da cidade, inclusive, negando o vivido ribeirinho que resiste nesse espaço (LIMA, 2013). 


\section{Os comuns urbanos, os resíduos da temporalidade ribeirinha}

A faixa de orla de Marabá abrange parte dos mais importantes núcleos urbanos da cidade, quais sejam: o núcleo Marabá Pioneira, o núcleo Cidade Nova, o núcleo Nova Marabá e o núcleo São Félix (mapa 01).

Atualmente três núcleos principais (Marabá Pioneira, Nova Marabá e Cidade Nova) e dois secundários (São Félix e Morada Nova) formam a estrutura urbana de Marabá, revelando uma cidade média multinucleada e, em alguns casos (Morada Nova), descontínua; configuração pouco comum às cidades médias brasileiras (TRINDADE JR.; LIMA; NUNES, 2013). Destaca-se, também, que foi incluída na análise a comunidade de pescadores da vila Espírito Santo, uma localidade que não faz parte direta do tecido urbano da cidade, mas que por este é influenciado e será diretamente impactada pela construção de um importante empreendimento, a Usina Hidrelétrica de Marabá.

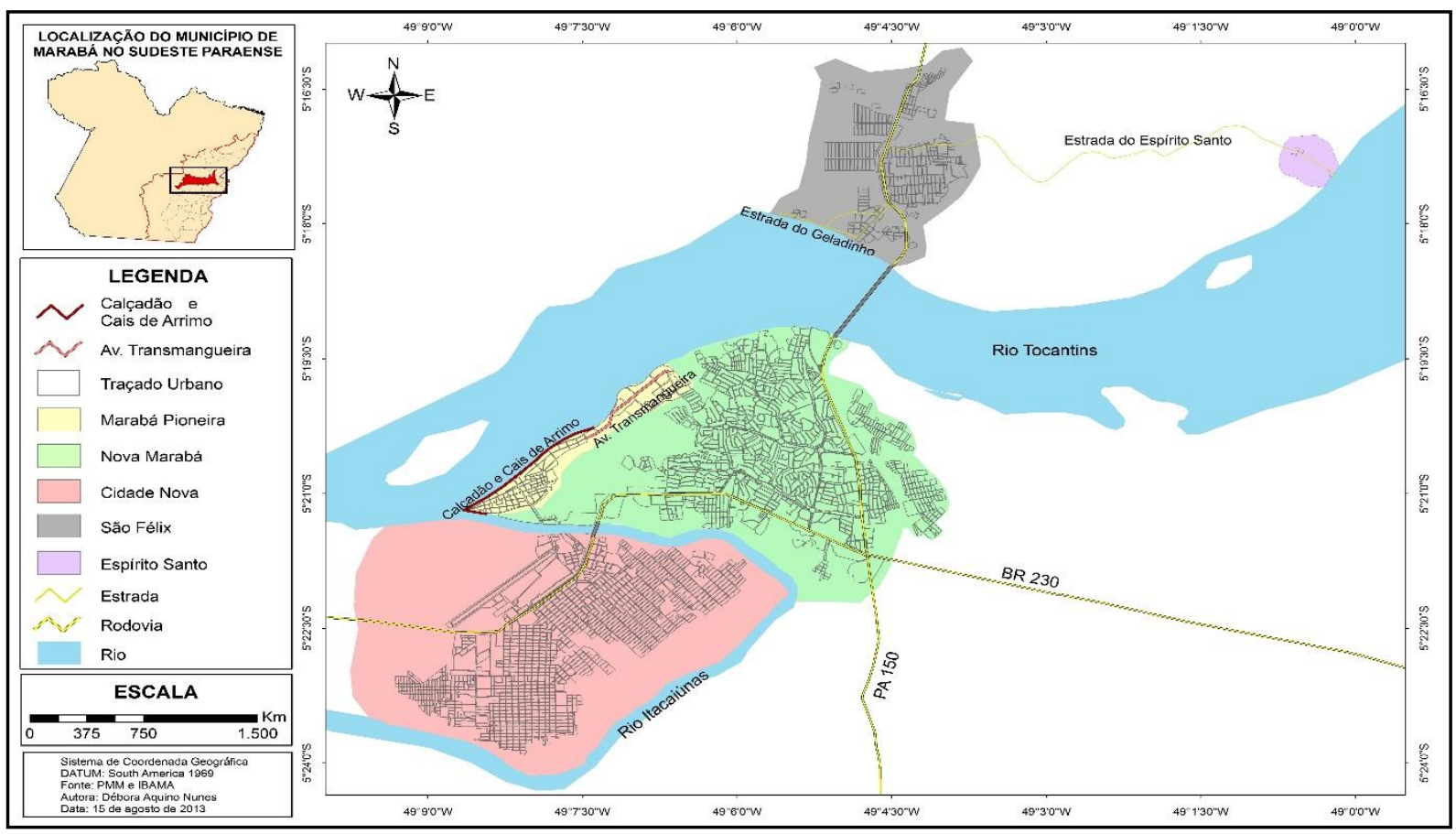

Mapa 01: Núcleos urbanos na orla de Marabá e a Vila Espírito Santo

Para entender como se dá a produção do espaço e a apropriação de comuns urbanos (rios e orla) no referencial empírico da pesquisa, na terceira e última parte deste trabalho será apresentada uma sistematização de dados qualitativos referentes à observação sistemática da paisagem e entrevistas ${ }^{2}$ gravadas com questões semiestruturadas realizadas com categorias diferenciadas de informantes dispostos ao longo da orla e da cidade de Marabá. Todos foram selecionados por serem os grupos mais representativos e que se destacavam, em diferentes escalas, no âmbito da produção social do espaço; estes foram divididos em diferentes categorias, a saber: a) chefes de famílias; b)

\footnotetext{
2 Parte das análises contidas neste artigo são resultado da pesquisa de mestrado, defendida no ano de 2013, intitulada "A ribeira \& a orla: espacialidades e territorialidades urbanas ribeirinhas em uma cidade amazônica em transformação". A maioria das entrevistas foram realizadas em dois momentos. 0 primeiro, de 11 a 18 de abril de 2010, na condição de bolsista PIBIC-CNPq, e o segundo, de 29 de abril a 11 de maio de 2012, na condição de mestrando do Programa de Pós-Graduação em Geografia da UFPA (PPGEO). As entrevistas foram organizadas a partir de temas específicos, em quadros explicativos com trechos das entrevistas onde os diferentes agentes e/ou grupos sociais manifestaram suas opiniões referentes aos questionamentos realizados pelo pesquisador sobre o objeto de estudo: a relação cidade-rio em Marabá.
} 
proprietários e representantes de estabelecimentos comerciais de pequeno e médio porte (bares, boates, lanchonetes, casas de show, náuticas, restaurantes); c) representante de empresa (da VALE, responsável pelo projeto ALPA); d) agentes/grupos que usam a orla apenas para o desenvolvimento de atividades lúdicas e turísticas; d) representantes do poder público da cidade de Marabá.

\section{Quadro 01 - A importância dos rios e da orla para os agentes/grupos atualmente}

\begin{tabular}{|c|c|c|}
\hline $\begin{array}{c}\text { Tipo de } \\
\text { importância }\end{array}$ & Informante & Entrevista \\
\hline $\begin{array}{l}\text { Subsistência } \\
\text { (pesca) }\end{array}$ & $\begin{array}{c}\text { Informante } \\
01\end{array}$ & $\begin{array}{l}\text { O meu gostar daqui é porque eu cheguei pra cá criança. Cheguei com idade } \\
\text { de dez anos e hoje eu tô com quarenta e nove. Então, eu já me acostumei } \\
\text { aqui. Mi casei e construí família aqui. Meus filhos nasceram aqui. Então, eu } \\
\text { acho bom demais! Meu lugar mesmo é esse aqui! Perto do rio tem fartura, } \\
\text { que nem eu te falei. A gente vai no rio e pega o peixe, pega a comida. Se } \\
\text { deixa a mulher cozinhando o arroz e vai lá, joga a tarrafa, um anzol. Se pega } \\
\text { o peixe, chega e faz a mistura e é assim. É mais fácil! [...]. (Morador 01, } 49 \\
\text { anos, pedreiro, } 02 \text { de maio de } 2012 \text { ). }\end{array}$ \\
\hline $\begin{array}{l}\text { Subsistência } \\
\text { (pesca) e } \\
\text { localização }\end{array}$ & $\begin{array}{l}\text { Informante } \\
02\end{array}$ & $\begin{array}{l}\text { É importante porque aqui a gente já tá na beira do rio, né. Quem mexe com } \\
\text { pesca tem de morar próximo do rio mesmo. Por conta disso que a gente } \\
\text { tem o barco, a gente precisa sair para os rios. É por isso que a gente mora } \\
\text { aqui, e melhor ainda por causa do sossego. E hoje, por causa desse } \\
\text { problema dessa hidrelétrica que vem aí, já tá muito deixando a gente, } \\
\text { assim, preocupado. Pra onde que vamos? O que vai fazer dessa profissão de } \\
\text { pescador? Sair pra cidade? Ninguém sabe como é que vai ficar. (Morador } \\
05,55 \text { anos, pescador, } 06 \text { de maio de } 2012 \text { ). }\end{array}$ \\
\hline $\begin{array}{l}\text { Subsistência } \\
\text { (pesca e venda } \\
\text { de produtos) }\end{array}$ & $\begin{array}{c}\text { Informante } \\
03\end{array}$ & $\begin{array}{l}\text { Tem! Hoje tem importância! Tem importância pra pesca, tem importância } \\
\text { pra minha vida de ambulante. Que depois surgiu a "orla", a gente trabalha } \\
\text { na orla vendendo bebida. Então, aquilo ali foi importante que tanto eu } \\
\text { trabalho no rio pescando, como eu trabalho na beira da orla vendendo a } \\
\text { minha cervejinha pra sobreviver [...]. Eu trabalho na pesca no decorrer da } \\
\text { semana, e na orla eu trabalho nos finais de semana. (Morador } 07,53 \text { anos, } \\
\text { pescadora e vendedora ambulante, } 09 \text { de maio de } 2012 \text { ). }\end{array}$ \\
\hline $\begin{array}{c}\text { Subsistência } \\
\text { (uso doméstico } \\
\text { da água) }\end{array}$ & $\begin{array}{c}\text { Informante } \\
04\end{array}$ & $\begin{array}{l}\text { Porque muitas pessoas sobrevivem desse rio. Muitos usam a água para } \\
\text { beber, para lavar. Apesar dela não ser uma água pura e nem limpa, usam } \\
\text { pra lavar roupa, outros para pescar. Tem muitas pessoas que sobrevivem } \\
\text { através desse rio, que precisam muito dele. Apesar d'eu não utilizar ele } \\
\text { dessas maneiras, mas têm muitas pessoas que usam ele e por isso ele é } \\
\text { importante. Essa água é muito importante para nós, com certeza! (Morador } \\
18,41 \text { anos, costureira, } 15 \text { de abril de } 2010 \text { ). }\end{array}$ \\
\hline $\begin{array}{l}\text { Subsistência } \\
\text { (transporte de } \\
\text { pessoas) }\end{array}$ & $\begin{array}{l}\text { Informante } \\
05\end{array}$ & $\begin{array}{l}\text { É importante porque pra mim... Como posso dizer, a minha convivência, } \\
\text { que eu não aguento mais trabalhar em outros tipos de serviço. Essa é a } \\
\text { primeira opção. Porque quando eu poder, assim, trabalhar pesado pra aqui } \\
\text { e pra acolá, não. Porque aí a gente se vira pra qualquer lado, mas aí quando } \\
\text { a gente não pode, a gente fica naquilo que tá dando pra gente viver e criar a } \\
\text { família. Inclusive esse aí é o meu filho, o mais velho. Aí a gente tá naquele } \\
\text { lugarzinho, tranquilo, né. Que o povo tem uns dizer, meu pais diziam "meu } \\
\text { filho, a pedra que não se atrepa não cria lodo". Então, a gente tem de ficar } \\
\text { num lugarzinho. Aonde tá arrumando hoje em dia (...). Aonde se tá } \\
\text { arrumando o pão pra você e pra sua família, ali tá bão pra você. Só isso, } \\
\text { meu problema é só esse, que aqui é que eu ganho meu pão. (Morador } 03,69 \\
\text { anos, barqueiro, } 02 \text { de maio de } 2012 \text { ). }\end{array}$ \\
\hline $\begin{array}{l}\text { Subsistência } \\
\text { (venda de } \\
\text { produtos) }\end{array}$ & $\begin{array}{l}\text { Informante } \\
06\end{array}$ & $\begin{array}{l}\text { Aqui é bom pra ganhar dinheiro. Pra quem gosta de trabalhar o dinheiro } \\
\text { não falta. Eu me acostumei, todo mundo que vem pra cá de fora gosta } \\
\text { porque aqui é a cidade pólo que chamam. Todo mundo se reúne para } \\
\text { trabalhar e ganhar dinheiro. [...] Aqui tem movimento, tem bar, restaurante, } \\
\text { churrascaria. Eu mexo com salgados, com bolo, vendo gelo, espetinhos, } \\
\text { essas coisas para sobreviver porque a aposentadoria não dá. (Morador 20, } \\
72 \text { anos, } 15 \text { de abril de 2010). }\end{array}$ \\
\hline
\end{tabular}




\begin{tabular}{|c|c|c|}
\hline Simbólica & $\begin{array}{c}\text { Informante } \\
07\end{array}$ & $\begin{array}{l}\text { [...] na minha opinião é porque eu gosto da beira do rio. Por ter nascido e } \\
\text { me criado aqui na beira desse rio eu acho muito bonito. Tanto que já tive } \\
\text { propostas em comprar, até adquirir uma área na zona rural, mas se não for } \\
\text { na beira do rio pra mim não serve! Porque lá eu gosto de pescar, eu gosto } \\
\text { de tomar banho no rio. Eu sou uma espécie de caboclo nato paraense e } \\
\text { gosto de estar na beira do rio. Eu adoro a beira do rio, o contato com a água. } \\
\text { Gosto de estar num barco, de estar numa ocupação nas águas. (Morador 13, } \\
58 \text { anos, ex-barqueiro e vigilante, } 02 \text { de maio de 2012). }\end{array}$ \\
\hline Econômica & $\begin{array}{l}\text { Informante } \\
08\end{array}$ & $\begin{array}{l}\text { Comercial, o interesse é comercial mesmo. Porque a cidade está crescendo. } \\
\text { As pessoas. Tem a Vale, né. Sinobras que tá aí crescendo também. Acho que } \\
\text { o empresário quer crescer junto. Marabá está ficando uma cidade bonita, } \\
\text { bem vista por todos. Todos que vem, vem com esse propósito de procurar } \\
\text { estar crescendo. [...] a vantagem é que as pessoas que tem vindo ao } \\
\text { restaurante, eles sempre dizem que é um lugar diferente. Sempre as } \\
\text { pessoas daqui mesmo da cidade, moram há muitos anos. Nós temos clientes } \\
\text { da Cidade Nova, da Nova Marabá, do Belo... Como é? Horizonte. Belo } \\
\text { Horizonte. Então, as pessoas vêm e dizem que aqui é muito diferente o } \\
\text { restaurante. Esse lugar aqui, ele é maravilhoso porque tem essa praia linda } \\
\text { aqui na frente. O interesse é comercial, financeiro, enfim. É uma série de } \\
\text { coisas que trouxeram pra Marabá um lugar diferente, pras pessoas que já } \\
\text { moram aqui há muitos anos, né. (Comerciante } 02,52 \text { anos, gerente de } \\
\text { restaurante, } 09 \text { de maio de 2012). }\end{array}$ \\
\hline Econômica & $\begin{array}{c}\text { Informante } \\
09\end{array}$ & $\begin{array}{l}\text { O meu negócio só foi montando aqui por causa do rio. Porque quando eu } \\
\text { vim para Marabá eu procurei vários pontos na cidade para montar meu } \\
\text { restaurante, mais aí, dentre... Dentre, por exemplo... Um rateio, a gente } \\
\text { optou pela beira do rio por causa que a gente já vinha de outras localidades } \\
\text { que tinham restaurante em beira de rio. E a gente sente o potencial do rio. } \\
\text { O rio é melhor para uma praça, para uma avenida, melhor para qualquer } \\
\text { coisa para se tocar um bar, um restaurante. Entendeu? Ele tem um } \\
\text { potencial muito forte. (Comerciante } 09,45 \text { anos, dono de restaurante, } 16 \\
\text { de abril de 2010). }\end{array}$ \\
\hline $\begin{array}{l}\text { Econômica } \\
\text { (transporte } \\
\text { fluvial) }\end{array}$ & $\begin{array}{c}\text { Informante } \\
10\end{array}$ & $\begin{array}{l}\text { Dentro da lógica do projeto Aços e Laminados do Pará, que compreende } \\
\text { não só uma usina siderúrgica, mas também um ramal ferroviário e um } \\
\text { terminal portuário, o rio e a área do rio representam pra nós a importância } \\
\text { da questão logística do projeto, uma vez que nós vamos receber todo o } \\
\text { carvão mineral oriundo da Colômbia, tá. E também parte do calcário, que } \\
\text { são insumos importantes dentro desse processo siderúrgico, eles virão... A } \\
\text { estratégia é que eles venham através do rio, através da hidrovia Tocantins. } \\
\text { [...] então, qual que é a nossa estratégia? Um terminal portuário em } \\
\text { Barcarena. Os navios chegam até Barcarena, descarregam o carvão mineral, } \\
\text { descarregam o calcário. Esse calcário e esse carvão mineral são colocados } \\
\text { em barcaças que desceriam, então, de Barcarena até Marabá, e seriam } \\
\text { descarregados através de um terminal portuário que nós construiríamos } \\
\text { dentro da área da própria ALPA. É um terminal pequeno, visando atender } \\
\text { justamente o objetivo logístico do projeto. Além disso, esse terminal } \\
\text { portuário também será utilizado pra que? Pra escoar parte da produção, } \\
\text { uma vez que uma parte da produção de aço nosso será exportado. } \\
\text { (Representante de empresa, } 32 \text { anos, relações institucionais do projeto, } 08 \\
\text { de maio de 2012). }\end{array}$ \\
\hline $\begin{array}{l}\text { Ponto turístico e } \\
\text { de lazer }\end{array}$ & $\begin{array}{c}\text { Informante } \\
11\end{array}$ & $\begin{array}{l}\text { Nossa, é um recurso muito rico pra cá, pras pessoas que vem de fora. } \\
\text { Porque é um lugar onde... É atração turística e para as pessoas aqui que } \\
\text { podem usufruir desse espaço maravilhoso que a gente tem, dessa } \\
\text { paisagem. Que, apesar de tudo, é um lazer que a gente tem pra caminhar, } \\
\text { pras pessoas mais idosas, mais jovens, em geral, completo. E a importância } \\
\text { para as pessoas daqui é que é um recurso de trabalho também que tem. Um } \\
\text { recurso de trabalho que as pessoas podem ter um modo de sobreviver, } \\
\text { vender as suas coisas, seu refrigerante, a sua balinha. Tem pessoas de } \\
\text { muito tempo que trabalham aqui. E turístico! Esse espaço aqui, ele } \\
\text { promove, nessa época junina e essas coisas, um espaço pra brincantes, de }\end{array}$ \\
\hline
\end{tabular}




\begin{tabular}{|c|c|c|}
\hline & & $\begin{array}{l}\text { jovens também. Pra ensaio. Época de carnaval é um espaço já reservado pra } \\
\text { isso. Eu acredito que seja muito turístico. (Agentes que realizam atividades } \\
\text { físicas e de lazer 06, } 27 \text { anos, Autônoma, } 05 \text { de maio de 2012). }\end{array}$ \\
\hline $\begin{array}{l}\text { Ponto turístico e } \\
\text { de lazer }\end{array}$ & $\begin{array}{c}\text { Informante } \\
12\end{array}$ & $\begin{array}{l}\text { Pra cidade, a orla, ela é como se fosse um ponto chave de toda a cidade. É } \\
\text { um ponto turístico aonde as pessoas vem se divertir, vem jantar, vem } \\
\text { passear com a família, ver o pôr-do-sol, ver o rio. Isso que é a importância } \\
\text { para a cidade. É um ponto turístico pra cidade de Marabá, e para os } \\
\text { moradores é um ponto de saúde, fazer caminhada. (Agentes que realizam } \\
\text { atividades físicas e de lazer } 05,41 \text { anos, enfermeiro, } 05 \text { de maio de 2012). }\end{array}$ \\
\hline $\begin{array}{l}\text { Econômica e } \\
\text { turística }\end{array}$ & $\begin{array}{l}\text { Informante } \\
13\end{array}$ & $\begin{array}{l}\text { Olha hoje a gente tem a orla como se fosse o cartão postal do município, né. } \\
\text { E assim, eu acho que todo mundo que chega pra visitar Marabá hoje tem no } \\
\text { entendimento que tem que conhecer a "orla" Sebastião Miranda. Que lá } \\
\text { você vai poder vislumbrar a beleza do rio Tocantins, essa coisa toda, né, } \\
\text { mas existem esses outros balneários, essas outras praias. O Geladinho é um } \\
\text { exemplo de uma praia muito bonita no rio Tocantins, também na } \\
\text { proximidade da ponte rodoferroviária, que oferece também um potencial } \\
\text { turístico muito grande [...]. (Representante do poder público 05, } 35 \text { anos, } \\
\text { Secretaria de Meio Ambiente de Marabá, } 08 \text { de maio de 2012). }\end{array}$ \\
\hline $\begin{array}{l}\text { Econômica e } \\
\text { turística }\end{array}$ & $\begin{array}{c}\text { Informante } \\
14\end{array}$ & $\begin{array}{l}\text { Rapaz, eu acho que todo o contato, toda a cidade que ela tem contato com o } \\
\text { rio, o rio exerce uma função fundamental na cidade. Principalmente uma } \\
\text { função de lazer, né. Mesmo que esse lazer não implique no uso do rio, no } \\
\text { uso pra banho, alguma coisa, mas esse lazer paisagístico, né. A questão da } \\
\text { paisagem. Você ter aquela paisagem, aquele por do sol no rio. Então, acho } \\
\text { que isso é uma coisa quem a gente nota que até a população mesmo } \\
\text { valoriza essa relação, né. Você vê pessoas acompanhando o por-do-sol, } \\
\text { sentado, olhando, batendo foto do por-do-sol. Então, quer dizer... E também } \\
\text { a visão do Tocantins é muito bonita nessa parte de Marabá, né. A gente vai } \\
\text { ter uma vegetação preservada do outro lado [...]. (Representante do poder } \\
\text { público 06, } 49 \text { anos, Secretaria de Planejamento e Controle de Marabá, } 10 \\
\text { de maio de 2012). }\end{array}$ \\
\hline $\begin{array}{c}\text { Simbólica e de } \\
\text { lazer }\end{array}$ & $\begin{array}{l}\text { Informante } \\
15\end{array}$ & $\begin{array}{l}\text { Eu acho que tem toda a importância. Se não for a maior importância, talvez } \\
\text { entre as duas ou três maiores importâncias para a cidade. Mesmo Marabá } \\
\text { hoje tendo outras atividades que não sejam ligadas essencialmente ao rio, a } \\
\text { gente não deixou de ter essa ligação com o rio. O rio foi importante desde o } \\
\text { descobrimento da cidade, no final do século de mil e oitocentos. No início } \\
\text { da implantação da cidade, em mil e novecentos, até a década de oitenta. O } \\
\text { rio foi "a grande estrada", era disseminador das notícias, por onde se } \\
\text { transportava as coisas, o lazer, enfim. Então, vamos colocar ai, durante } \\
\text { oitenta anos basicamente a cidade viveu totalmente voltada para o rio... } \\
\text { Embora hoje, é claro, tenha se voltado para outras coisas, mas isso ainda } \\
\text { está muito vivo na memória das pessoas. E certamente mesmo que hoje se } \\
\text { volte para outras coisas, eu acredito que jamais o rio vai deixar de ter uma } \\
\text { grande importância, assim, no imaginário, no prazer, no lazer do } \\
\text { marabaense [...]. (Representante do poder público } 04,61 \text { anos, Casa da } \\
\text { Cultura de Marabá, } 03 \text { de maio de 2012). }\end{array}$ \\
\hline Turística & $\begin{array}{l}\text { Informante } \\
16\end{array}$ & $\begin{array}{l}\text { É como eu disse, essa importância, ela é totalmente turística. Eu acredito, } \\
\text { eu acredito não, nós já identificamos através de um trabalho que nós } \\
\text { realizamos aqui para a escolha do símbolo turístico. A "orla" ela é um dos } \\
\text { principais atrativos turísticos nosso. Ela é o nosso cartão postal, mesmo } \\
\text { porque, por a gestão ter feito a "orla", ter criado aquele equipamento todo, } \\
\text { aquela beleza, a contemplação natural do rio ainda é um atrativo. A geração } \\
\text { de emprego e renda aos arredores, com bares e restaurantes, locais de } \\
\text { entretenimento e lazer é importante para o turismo. Pra cidade, a "orla", ela } \\
\text { tem uma conotação especificamente turística. (Representante do poder } \\
\text { público } 07,45 \text { anos, Secretaria de Turismo, } 16 \text { de abril de 2010). }\end{array}$ \\
\hline
\end{tabular}

Fonte: entrevistas realizadas em trabalho de campo, em abril de 2010 e abril/maio de 2012.

Para os moradores, os rios e a orla são importantes para a sua subsistência, principalmente, por 
conta da pesca, atividade que é desenvolvida tanto para o próprio consumo, quanto como único meio de obter renda através da venda do pescado aos diversos donos de bares, de restaurantes e na feira do peixe. Por conta de estarem localizados na beira dos rios, muitos moradores - inclusive os que não se identificam como pescadores - , sejam eles crianças, jovens ou adultos, fazem o uso do saber e da arte pesqueira com vistas a assegurar o alimento do dia, principalmente, em momentos de dificuldade financeira e de desemprego.

O transporte fluvial, por sua vez, é destacado como um elemento importante para o desenvolvimento da dinâmica socioespacial dos moradores. Isso porque ele é utilizado para visitar parentes e amigos em localidades distantes e das ilhas, para a realização da pesca ao longo dos rios ou para obter alguma renda através do transporte de pessoas e mercadorias. Além disso, muitas pessoas também sobrevivem com o dinheiro obtido do aluguel de barcos, canoas e rabetas aos visitantes e turistas.

A existência de espaços de lazer e entretenimento ao longo da orla, os famosos balneários, e a construção do calçadão e do cais de arrimo no núcleo Marabá Pioneira, possibilitaram aos moradores desenvolver atividades como a venda de diversos tipos de produtos aos visitantes e aos turistas uma forma de obter um "trocado a mais" que os ajuda a sobreviver e a complementar a sua renda. São doces, salgados, frutas etc., além dos mais variados tipos de bebidas alcoólicas e não-alcoólicas; todos produtos ligados ao tipo de dinâmica que ali se desenvolve, que está mais associado ao uso das "praias", as danças e encontros nas festas, as conversas nos bares, boates etc. Desse modo, esses agentes/grupos competem pelos clientes com os maiores e mais organizados estabelecimentos comerciais, que estão localizados na orla.

A importância simbólica da orla e dos rios também é destacada como elemento essencial na vida dos moradores. Para eles, que se banham, navegam e pescam, as águas são um referencial de vida e de uma história; esta que traduz de forma mais direta, porém, complexa, a sua ligação com os rios e com a floresta.

Por seu turno, os agentes que realizam atividades físicas (passeios, caminhadas, corridas etc.) entendem que ali se configura não só um espaço de sobrevivência da população que vende seus produtos, mas também de festa, de brincadeiras, de folia, assim como conformam espaços de reunião da família, de realização de atividades físicas, de saúde, de lazer e de turismo; um mosaico urbano que reúne usos diversos, formas de apropriação desencontradas, desiguais, mas que (co)existem e dão vida à orla marabaense.

Por outro lado, a importância do potencial econômico da orla também é apontada como algo essencial para parte dos agentes/grupos. Para os informantes comerciantes, o interesse em estar e desenvolver atividades nesse espaço é, predominantemente, econômico. Assim, buscam obter lucros por intermédio das vantagens de terem seus restaurantes localizados numa cidade que é lócus de grandes investimentos e negócios na região (TAVARES, 1999), e que define seu dinamismo em função da forte centralidade econômica e política exercida no contexto sub-regional do sudeste paraense (TRINDADE JR., 2011).

Sobre a importância econômica relacionada ao transporte fluvial em maior escala, o representante de uma grande empresa destaca como é essencial à logística do projeto ao qual faz parte os rios e o espaço da orla de Marabá. Para ele, a instalação da Hidrovia Araguaia-Tocantins e do terminal portuário em Marabá possibilitará a empresa aperfeiçoar e intensificar o processo produtivo e, com isso, obter maiores vantagens econômicas e lucros.

Os representantes do poder público, no geral, entendem que a faixa de contato entre a terra e a água configura o "cartão postal da cidade". Nesse sentido, embora eles reconheçam que ela é importante pela ligação simbólica que apresenta com os rios, o seu maior destaque se dá por conta das amenidades naturais existentes, da geração de emprego e de renda e da sua afirmação como o principal ponto turístico e de entretenimento em Marabá.

Assim, percebemos um complexo e contrário movimento, que é o de encontro (que se dá através da inclusão e exclusão de conteúdos sociais) de uma temporalidade ribeirinha ligada ao tempo da 
Marabá antiga, do caucho, da castanha, do cristal de rocha e diamante, dos rios e da floresta, com uma temporalidade modernizante e de economia mais dinâmica, do transporte de minérios, da geração de energia hidroelétrica, do turismo, das micaretas etc.

É por conta de todos esses usos, de todas essas práticas e de toda essa representatividade, que os rios e a orla configuram-se como elementos essenciais aos diversos grupos de entrevistados, e notadamente como comuns urbanos para boa parte daqueles que não tem no espaço imediato entre terra e água um referencial predominantemente econômico.

\section{Considerações Finais}

É por entre estas dinâmicas e temporalidades múltiplas, (co)existentes e conflitantes que se desenvolve, então, a relação cidade-rio em Marabá e em sua orla fluvial; espaço que edificou comuns urbanos associados aos rios e à floresta e que foi alvo de diferentes formas de dominação, apropriação e uso ao longo do tempo, que estão associadas, respectivamente, tanto ao início da circulação regional e a utilização comum dos rios e da floresta, principalmente como meios de subsistência e referencial de vida, quanto ao processo de modernização capitalista do espaço da Amazônia no período recente.

A temporalidade modernizante estaria associada ao que Lefèbvre (1974) denomina de "tendência ideologicamente dominante", aquela que privilegia o aproveitamento econômico, que busca a maximização dos lucros, de riquezas, de capital; que reparte, segundo a sua vontade e de acordo com a divisão social do trabalho e os interesses do capital, as partes e as parcelas de espaço.

Por fim, a temporalidade ribeirinha, que é sufocada pelo processo de modernização do espaço e pelo empreendedorismo urbano, é (re)produzida por meio de práticas sociais e comuns urbanos existentes que refletem usos e equipamentos ligados aos rios e à floresta, tais como os pequenos e improvisados portos e trapiches, as rampas de acesso aos rios, a feira do peixe, o amontoado de barcos, canoas e rabetas aportados ao longo da orla, os improvisados estaleiros e a construção naval de pequeno porte, o uso doméstico da água dos rios, os banhos de fim de tarde, a circulação fluvial de pequeno e médio porte, a pesca, a criação de animais (galinhas, porcos), o cultivo de várzea e as festas de santo.

\section{Referências}

CARLOS, A. F. A. A condição espacial. São Paulo: Contexto, 2011.

CASTRO, E. Urbanização, pluralidade e singularidades das cidades amazônicas. In: Cidades na floresta. São Paulo: Annablume, 2008. p. 11-39.

EMMI, M. F. A oligarquia do Tocantins e o domínio dos castanhais. 2ª ed. Belém: UFPA/NAEA, 1999.

HARVEY, D. A produção capitalista do espaço. São Paulo: Annablume, 2005.

A liberdade da cidade. In: Cidades rebeldes: Passe Livre e as manifestações que tomaram as ruas do Brasil. MARICATO, E. São Paulo: Boitempo, 2013. p. 27-34.

A criação de bens comuns urbanos. In: Cidades rebeldes: do direito à cidade à revolução urbana. São Paulo: Martins Fontes, 2014. p. 134-189.

LEFEBVRE, H. La productión de l'espace. Paris: Anthropos, 1974.

. $O$ direito à cidade. 4 a ed. São Paulo: Centauro, 2006.

. A revolução urbana. Belo Horizonte: UFMG, 2008a. 
Espaço e política. Belo Horizonte. UFMG, 2008b.

LIMA, M. M. A ribeira \& a orla: espacialidades e territorialidades urbanas ribeirinhas em uma cidade amazônica em transformação. Dissertação (mestrado em geografia) - Instituto de Filosofia e Ciências Humanas, Universidade Federal do Pará. Belém, 2013. 256 f.

A produção social do espaço e a relação cidade-rio na ribeira de Marabá-PA: modernização, conflitos e resistências. GEOUSP: espaço e tempo. São Paulo, v. 20, p. 267-280, 2016.

OLIVEIRA, J. A. As cidades da Amazônia: novas territorialidades e velhas exclusões reencontradas. Caderno Prudentino de Geografia. São Paulo, v. 21, p. 53-70, 1999.

Cidades na selva. Manaus: Valer, 2000.

TAVARES, M. G. A dinâmica espacial da rede de distribuição de energia elétrica no Estado do Pará (1960-1996). Rio de Janeiro, 1999. Tese (Doutorado em Geografia) - Programa de Pós-Graduação em Geografia, Universidade Federal do Rio de Janeiro.

TRINDADE JR., S. C.; SANTOS, E. R. C.; RAVENA, N. A cidade e o rio: espaço e tempo na orla fluvial de Belém. In: TRINDADE JR, S. C.; SILVA, M. A. P. (Orgs.). Belém: a cidade e o rio na Amazônia. Belém: EDUFPA, 2005. p.12-43.

TRINDADE JR., S. C.; AMARAL, M. D. B.; SILVA, M. A. P. Das "janelas" às "portas" para os rios: compreendendo as cidades ribeirinhas na Amazônia. In: TRINDADE JR., S. C.; TAVARES, M. G. (Orgs.). Cidades ribeirinhas na Amazônia: mudanças e permanências. Belém: EDUFPA, 2008. p. 27-47.

TRINDADE JR., S. C.; LIMA, M. M.; NUNES, D. A. Velha Marabá: mudanças e permanências no centro histórico de uma cidade média da Amazônia brasileira. In: SPOSITO, M. E. B.; FERNANDES, J. A. V. R. (Org.). A nova vida do velho centro nas cidades portuguesas e brasileiras. Porto: CEGOT, 2013. p. 255270.

TRINDADE JR., S. C. Cidades na floresta: os "grandes objetos" como expressões do meio técnicocientífico informacional no espaço amazônico. Revista do Instituto de Estudos Brasileiros, São Paulo, Instituto de Estudos Brasileiros, n. 51, p. 113-137, mar./set. 2010.

Cidades médias na Amazônia oriental: das novas centralidades à fragmentação dos territórios. In: Anais do XIV Encontro da Associação Nacional de Pós-graduação e Pesquisa em Planejamento Urbano e Regional. Rio de Janeiro, 2011. CD-Rom.

VELHO, O. G. Frentes de expansão e estrutura agrária: estudo do processo de penetração numa área da Tranzamazônica. Rio de Janeiro: Zahar, 1972. 